\title{
Loop wheel bicycle
}

\author{
Shubham Bankar \\ Guided by Professor, Department of Mechanical Engineering
}

\begin{abstract}
A Loop wheel is a wheel with integral suspension, designed for higher shock-absorbing performance and better comfort. Loop wheels offer you a smoother ride. They're more comfortable than usual wheels: the carbon springs absorb exhausting vibration, in addition to the bumps and the shocks. They're extraordinarily robust and durable. Material used for manufacturing loop wheel springs is composite material which carefully developed to offer ultimate compression and lateral stability as well as durability. Specially-designed connectors attach the springs to the hub and rim. The three loops in every wheel work along as a self-correcting system. This spring combination between the hub and the rim of the wheel provides better suspension that steadily adjusts to uneven terrain cushioning the rider from abnormalities in the road. In effect, the hub floats inside the rim, adjusting continuously as shocks from the uneven road hit the rim of the wheel. The spring configuration permits the torque to be transferred smoothly between the hub and the rim.
\end{abstract}

Keywords: Loop wheel, springs, hub and rim, shocks

\section{INTRODUCTION}

A wheel is a circular part that's meant to rotate on an axle bearing. The wheel is one of the essential parts of the wheel and axle which is one of the six simple machines. Wheels, in conjunction with axles, enable heavy objects to be moved simply facilitating movement or transportation while supporting a load, or performing labour in machines. Wheels are also used for various alternative functions, such as a ship's wheel, steering wheel, potter's wheel and flywheel. Common examples are found in transport applications. A wheel greatly reduces friction by facilitating motion by rolling along with the use of axles. For the for wheels to rotate, a moment has to be applied to the wheel about its axis, either by means of gravity, or by applying another external force or torsion.

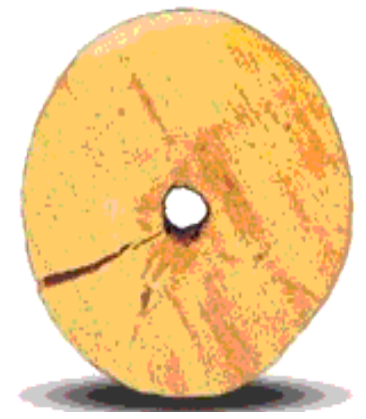

\section{Recent Advancements in cycles}

\section{Track bicycle}

A track bicycle or track bike is a bicycle optimized for racing at a velodrome or outdoor track. Unlike road bicycles, the track bike is a fixed-gear bicycle; thus, it has only a single gear ratio and has neither a freewheel nor brakes. Tires are narrow and inflated to high pressure to reduce rolling resistance. Tubular tires are most often used in track racing and training, though advances in clincher tire design have seen them being used somewhat more often.

\section{Racing bicycle}

A racing bicycle, also known as a road bike, is a bicycle designed for competitive road cycling, a sport governed by according to the rules of the Union Cyclist International (UCI). The UCI rules were altered in 1934 to exclude recumbent bicycles.

The most important characteristics about a racing bicycle are its weight and stiffness which determine the efficiency at which the power from a rider's pedal strokes can be transferred to the drive-train and subsequently to its wheels. To this effect racing bicycles may sacrifice comfort for speed. The drop handlebars are positioned lower than the saddle in order to put the rider in a more aerodynamic posture. 


\title{
International Advanced Research Journal in Science, Engineering and Technology
}

Vol. 5, Issue 11, November 2018

\section{Problem statement}

In the conventional bicycles there no any type of suspension system. The spokes attached to rim has less load bearing capacity for special purpose cycles. The aim of the project is to design new type of wheel with hub, rim and tyre to provide suspension as well as to support rim and provide better bearing capacity.

\author{
Objective of the project \\ 1) To design better shock-absorbing performance. \\ 2) To give smoother ride. \\ 3) To increase load bearing capacity.
}

\section{Future scope}

In this project we will design and fabricate a loop-wheel bicycle which will be able to have extra feature of shock absorption and also the better load bearing capacity. The project will contain a bicycle with an improved wheel. The wheel will be replaced from conventional spoked-rim system to leaf spring or loop spring. The wheel will consist Axle, Hub, Rim, Tyre and Leaf/loop springs. All parts will be mounted in wheel so as to maintain its centre of gravity.

\section{LITERATURE REVIEW}

GulurSiddaramanna, Shiva Shankar[1], the automobile industry has shown increased interest in the replacement of steel spring with fibreglass composite leaf spring due to high strength to weight ratio. Therefore; the aim of this paper is to present a low cost fabrication of complete mono composite leaf spring and mono composite leaf spring with bonded end joints. Also, general study on the analysis and design. A single leaf with variable thickness and width for constant cross sectional area of unidirectional Glass Fiber Reinforced Plastic (GFRP) with similar mechanical and geometrical properties to the multileaf spring, was designed, fabricated (hand-layup technique) and tested. Computer algorithm using C-language has been used for the design of constant cross-section leaf spring. The results showed that an spring width decreases hyperbolically and thickness increases linearly from the spring eyes towards the axle seat. The finite element results using ANSYS software showing stresses and deflections were verified with analytical and experimental results. The design constraints were stresses (Tsai-Wu failure criterion) and displacement. Compared to the steel spring, the composite spring has stresses that are much lower, the natural frequency is higher and the spring weight is nearly 85 $\%$ lower with bonded end joint and with complete eye unit.

Pankaj Saini, Ashish Goel and Dushyant Kumar [2], as reducing weight and increasing strength of products are high research demands in the world, composite materials are getting to be up to the mark of satisfying these demands. In this paper reducing weight of vehicles and increasing the strength of their spare parts is considered. As leaf spring contributes considerable amount of weight to the vehicle and needs to be strong enough, a single composite leaf spring is designed and it is shown that the resulting design and simulation stresses are much below the strength properties of the material satisfying the maximum stress failure criterion.

Baviskar A. C., Bhamre V. G. And Sarode S. S[3], analysis of leaf spring. The suspension system in a vehicle significantly affects the behaviour of vehicle, i.e. vibration characteristics including ride comfort, stability etc. Leaf springs are commonly used in the vehicle suspension system and are subjected to millions of varying stress cycles leading to fatigue failure. A lot of research has been done for improving the performance of leaf spring. Now the automobile industry has shown interest in the replacement of steel spring with composite leaf spring. In general, it is found that fibreglass material has better strength characteristic and lighter in weight as compare to steel for leaf spring. In this paper there is reviewed some papers on the design and analysis leaf spring performance and fatigue life prediction of leaf spring. There is also the analysis of failure in leaf spring. Also the analysis of leaf spring with ansys is done. The automakers can reduce product development cost and time while improving the safety, comfort, and durability of the vehicles they produce.

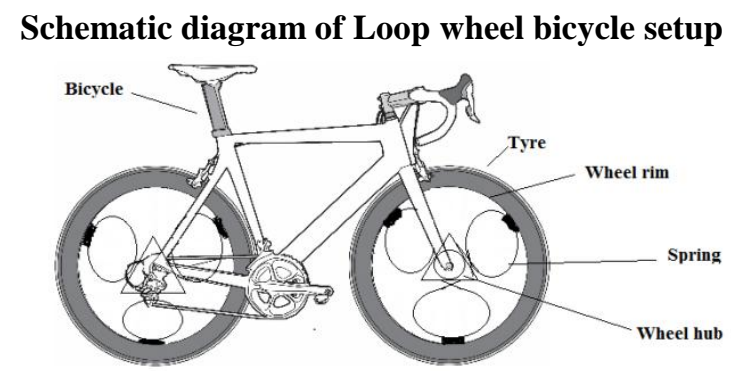

Figure.1. Loop wheel bicycle setup 


\section{International Advanced Research Journal in Science, Engineering and Technology}

Vol. 5, Issue 11, November 2018

\section{D model of setup}

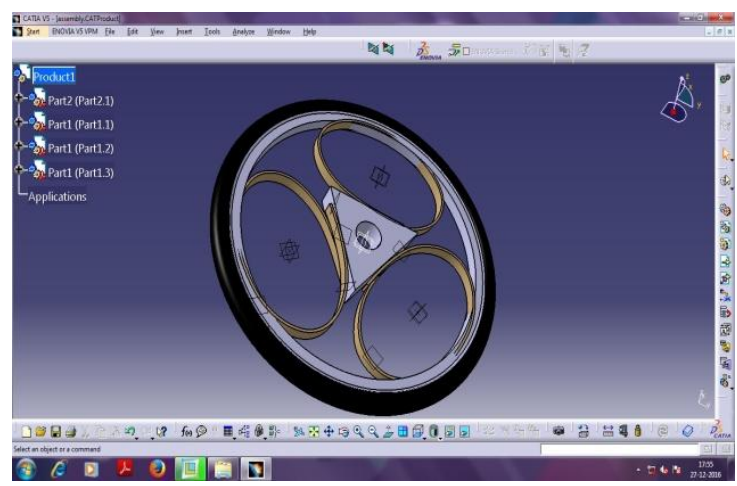

Figure.2. Catia model of Loop wheel

\section{Components Used}

\section{Bicycle}

A bicycle, often called a bike or cycle, is a human-powered, pedal-driven, single-track vehicle, having two wheels attached to a frame, one behind the other. A bicycle rider is called a cyclist, or bicyclist.

Tyre

A tire or tyre is a ring-shaped covering that fits around a wheel rim to protect it and enable better vehicle performance by providing a flexible cushion that absorbs shock while keeping the wheel in close contact with the ground. The word itself may be derived from the word "tie," which refers to the outer steel ring part of a wooden cart wheel that ties the wood segments together.

\section{Wheel Rim}

The rim is commonly a metal extrusion that is butted into itself to form a hoop, though may also be a structure of carbon fiber composite, and was historically made of wood. Some wheels use both an aerodynamic carbon hoop bonded to an aluminium rim on which to mount conventional bicycle tires. A bicycle wheel is a wheel, most commonly a wire wheel, designed for a bicycle.

\section{Leaf Spring/Loop Spring}

A leaf spring is a simple form of spring commonly used for the suspension in wheeled vehicles. Originally called a laminated or carriage spring, and sometimes referred to as a semi-elliptical spring or cart spring, it is one of the oldest forms of springing, dating back to medieval times. A leaf spring can either be attached directly to the frame at both ends or attached directly at one end, usually the front, with the other end attached through a shackle, a short swinging arm.

\section{Triangular Wheel Hub}

A Triangular hub is the centre part of a bicycle wheel. It consists of an axle, bearings and a hub shell. Hub shells can be one-piece with press-in cartridge or free bearings or, in the case of older designs, the flanges may be affixed to a separate hub shell. The hub is the centre of the wheel, and typically houses a bearing, and is where the axle is mounted inside it.A hub less wheel (also known as a rim-rider or centerless wheel) is a type of wheel with no centre hub

\section{Calculation \\ LEAF SPRING \\ Calculations}

Distribution of body weight for average weight of $60 \mathrm{~kg}$ per person

$$
\begin{aligned}
& \text { Head }=\frac{8.26}{100} * 60=4.956 \mathrm{~kg} \\
& \text { Thorax }=\frac{20.1}{100} * 60=12.06 \mathrm{~kg} \\
& \text { Abdomen }=\frac{13.06}{100} * 60=7.836 \mathrm{~kg} \\
& \text { Pelvis }=\frac{13.66}{100} * 60=8.196 \mathrm{~kg} \\
& \text { Total arm }=\frac{5.7}{100} * 60=3.42 \mathrm{~kg} \\
& \text { Thigh }=\frac{10.56}{100} * 60=6.3 \mathrm{~kg}
\end{aligned}
$$

Total effective weight Distribution in combination

$$
\begin{aligned}
& \text { Head \& Neck }=\frac{6.81}{100} * 60=4.086 \mathrm{~kg} \\
& \text { Trunk }=\frac{43.02}{100} * 60=25.81 \mathrm{~kg}
\end{aligned}
$$




\section{International Advanced Research Journal in Science, Engineering and Technology}

Vol. 5, Issue 11, November 2018

$$
\begin{aligned}
& \text { 2* total arm }=\frac{4.715}{100} * 60=2.829 * 2=5.658 \mathrm{~kg} \\
& \mathbf{2} * \text { thigh }=\frac{14.47}{100} * 60=8.68 * 2=17.364 \mathrm{~kg}
\end{aligned}
$$

Total effective weight $=4.086+25.81+5.658+17.364$

$$
=52.918 \mathrm{Kg}
$$

\section{Now calculation for total load on each wheel}

As we know that the total weight if get distributed on two wheels

And total approximate weight of cycle $=14 \mathrm{Kg}$

Hence load on each wheel, $\mathrm{w}=30 \mathrm{~kg}+7 \mathrm{~kg}=37 * 9.81=362.97 \mathrm{~N}$

Load due to tractive force, $\mathrm{f}=\mu * \mathrm{w}=0.02 * 362.97=7.2594 \mathrm{~N}$

Total load on each wheel, $\mathrm{F}=\mathrm{w}+\mathrm{f}=362.97+7.2594=370.2294 \mathrm{~N}$

Chain design

Selecting standard chain used in cycle as Chain -06 B

Pitch $-9.525 \mathrm{~mm}$

1. Roller diameter, $\mathrm{d} 1=6.35 \mathrm{~mm}$

Width' b1 $=5.72 \mathrm{~mm}$

Transverse pitch $\mathrm{p}_{\mathrm{t}}=54.85 \mathrm{~mm}$

$\mathrm{z} 1=18$

$\mathrm{z} 2=44$

2. Approximate centre distance,

$\mathrm{a}=40 * \mathrm{P}$

$\mathrm{a}=40 * 9.525$

$\mathrm{a}=381 \mathrm{~mm}$

3. No of links,

$$
\begin{aligned}
\mathrm{L}_{\mathrm{n}}=2(\mathrm{a} / \mathrm{p}) & +\left(\frac{z 1+z 2}{2}\right)+\left(\frac{z 2-z 1)}{2 \pi}\right) *\left(\frac{p}{a}\right) \\
= & 2(381 / 9.525)+\left(\frac{18+44}{2}\right)+\left(\frac{44-18}{2 \pi}\right) *\left(\frac{9.525}{381}\right)
\end{aligned}
$$

\section{Leaf Spring}

Calculate maximum stress

We used C20 material

Tensile strength $=560 \mathrm{~N} / \mathrm{mm}^{\wedge} 2$

$\sigma$ max of C20 material $=560 / 2=280 \mathrm{~N} / \mathrm{mm}^{\wedge} 2$

Given data:

$\mathrm{F}=370.22 \mathrm{~N}$

Major Axis of loop spring $=\mathrm{L}=300 \mathrm{~mm}$

Minor axis of loop spring $=\mathrm{h}=200 \mathrm{~mm}$

$\mathrm{E}=200 \mathrm{MPa}$

Width of spring $=b=25.4 \mathrm{~mm}$

Thickness of spring $=\mathrm{t}=5 \mathrm{~mm}$

$$
\begin{aligned}
\sigma \max & =\frac{3 F L}{2 n b \mathrm{t}^{2}} \\
& =\frac{3 * 370.22 * 300}{2 * 1 * 25.4 * 5^{2}} \\
& =262.36 \mathrm{~N} / \mathrm{mm} 2<280 \mathrm{~N} / \mathrm{mm} 2
\end{aligned}
$$

Hence design safe.

\section{Calculation of max. Deflection:}

$$
\begin{aligned}
\delta \max & =\frac{3 F L^{3}}{8 E n b t^{3}} \\
& =\frac{2 * 370.22 * 300^{3}}{8 * 2 * 10^{5} * 1 * 25.4 * 5^{3}} \\
& =5.90 \mathrm{~mm}
\end{aligned}
$$

\section{COST ESTIMATION}

Cost estimation may be defined as the process of forecasting the expenses that must be incurred to manufacture a product. These expenses take into a consideration all expenditure involved in a design and manufacturing with all 


\section{International Advanced Research Journal in Science, Engineering and Technology}

Vol. 5, Issue 11, November 2018

related services facilities such as pattern making, tool, making as well as a portion of the general administrative and selling costs.

\section{PURPOSE OF COST ESTIMATION}

1. To determine the selling price of a product for a quotation or contract so as to ensure a reasonable profit to the company.

2. Check the quotation supplied by vendors.

3. Determine the most economical process or material to manufacture the product.

4. To determine standards of production performance that may be used to control the cost.

\section{SAFETY PRECAUTIONS}

The following points should be considered for the safe operation of machine and to avoid accidents:-

- All the parts of the machine should be checked to be in perfect alignment.

- All the nuts and bolts should be perfectly tightened.

- The operating switch should be located at convenient distance from the operator so as to control the machine easily.

- The inspection and maintenance of the machine should be done from time to time.

\section{Advantages:}

1) Better shock-absorbing performance.

2) Greater comfort.

3) Smoother ride.

4) More comfortable than standard wheels.

5) They are extremely strong.

\section{REFERENCES}

[1]. GulurSiddaramanna, Shiva Shankar and SambagamVijayarangan, "Mono Composite Leaf Spring for Light Weight Vehicle - Design, End Joint Analysis and Testing”, MATERIALS SCIENCE (MEDŽIAGOTYRA), ISSN 1392-1320, Vol. 12, Issue No. 3. 2006 , PP $220-225$.

[2]. Pankaj Saini, Ashish Goel andDushyant Kumar, "Design and Analysis of Composite Leaf Spring for Light Vehicles", International Journal of Innovative Research in Science, Engineering and Technology, ISSN: 2319-8753, Vol. 2, Issue 5, May 2013, PP 1-10.

[3]. Baviskar A. C., Bhamre V. G. andSarode S. S., "Design and Analysis of a Leaf Spring for automobile suspension system- A Review", International Journal of Emerging Technology and Advanced Engineering, ISSN 2250-2459, Volume 3, Issue 6, June 2013, PP 406-410.

[4]. Mr. Tharigonda Niranjan Babu, Mr P. Bhaskar and Mr. S. Moulali, "Design and Analysis of Leaf Spring with Composite materials", INTERNATIONAL JOURNAL OF ENGINEERING SCIENCES \& RESEARCHTECHNOLOGY, ISSN: 2277-9655, Babu, 3(8): August, 2014, PP 759-756.

[5]. HolfgangTrauthein, "Loop-wheel suspension system development status", Engineering Consultant, D-7758 Meersburg, Federal Republic of Germany, Formarly of Lokeeed Research and Engineering center, Huntsville, Al. USA.

[6]. A advertising poster "Urgent Operational Requirement: Build your own loopwheel".

[7]. Info@Loop-wheels.com, A advertising poster, "Loop-wheels : because sometimes it's good to reinvent the wheel". 